Jurnal Keperawatan Padjadjaran

ISSN 2338-5324 (print)

ISSN 2442-7276 (online)

Online di http://jkp.fkep.unpad.ac.id

DOI : $10.24198 / \mathrm{jkp}$

\title{
Depression, Recurrence, and Perceptions of Physical Fitness among CHD Patients: A Comparison based on Participation in Phase II Cardiac Rehabilitation Program
}

\author{
Aan Nuraeni*, Atlastieka Praptiwi, Ikeu Nurhidayah \\ Faculty of Nursing, Universitas Padjadjaran, Bandung, Indonesia \\ Corresponding email: aan.nuraeni@unpad.ac.id
}

Submitted: 04-10-2020 Accepted: 17-12-2020 Published: 27-12-2020

\begin{abstract}
Coronary heart disease (CHD) patients experience various physical and psychological changes after an acute attack. Depression has been identified as a substantive psychological problem in CHD patients. Cardiac rehabilitation (CR) intends to restore optimal physical and psychological condition of the patients. However, less attention is bestowed towards the psychological aspect of CR. Research on the effects of CR on patient psychological problems has not been discussed in many studies in Indonesia. This study aimed to compare depression, recurrence, and fitness levels among CHD patients based on participation in Phase II CR Program. This research used a quantitative comparative method involving 66 CHD patients recruited by a purposive sampling technique. After applying the selection criteria for this study, the patients were assigned to the CR group $(\mathrm{nCR}=29)$ and the non-CR group $(\mathrm{nNCR}=37)$. Data were collected using the Beck Depression Inventory-II (BDI II) and instruments developed by researchers to measure recurrence and fitness levels. Data were analyzed using frequency distribution, chi-squared, and Mann-Whitney tests. Depression experienced by CHD patients in both groups with mean in non-CR and CR groups of $11.11( \pm 7.8)$ and $8.59( \pm 6.5)$, respectively. There was no significant difference in depression level among the groups ( $\mathrm{p}>0.05)$ ). Meanwhile, as many as $45 \%$ of the patients in the CR group and $22 \%$ in the non-CR group had never experienced chest pain (recurrence) within the past month. In addition, the physical fitness was perceived increased by $90 \%$ of the patients in the CR group and $0 \%$ in the non-CR group. It was also found that there were significant differences in the recurrence and physical fitness among the two groups $(\mathrm{p}<0.05)$. Patients participating in Phase II CR program had a better perception of physical fitness and a lower frequency of chest pain than patients in the non-CR group. Although the depression level in patients in the two groups did not differ significantly, patients in the non-CR group scored higher in depression. Accordingly, assessment and psychosocial interventions need to be improved to optimize CR program services.
\end{abstract}

Keywords: Cardiac rehabilitation, chest pain, coronary heart disease, depression, physical fitness, recurrence.

Volume 8 Issue 3 December 2020 


\section{Introduction}

Global data indicates that every year, many patients with coronary heart disease die and suffer from chronic disabilities (Hoseini et al., 2013). In Indonesia, this disease showed a high number of new incidence and recurrences. The recurrence rate of CHD reached $40 \%$ of all patients (Indrawati, 2012); this will increase the number of people with cases if new cases continue to grow. Based on the latest data from Indonesian Basic Health Research, 15 out of 1000 Indonesians were diagnosed with CHD (Ministry of Health of the Republic of Indonesia, 2018).

Following a heart attack, CHD patients require various adjustments as a result of multiple changes. These changes include physical limitations, fatigue, frequent chest pain, shortness of breath, and sexual disturbances (Nuraeni et al., 2016; Rosidawati et al., 2016). Furthermore, the incidence of anxiety (40\%) and depression (62\%) in CHD patients after an acute attack was relatively high (Nuraeni et al., 2019; Rachmi et al., 2018). Overall, CHD patients' quality of life a few months after going through the acute phase was relatively low (Nuraeni et al., 2019; Nurhamsyah, 2019).

To overcome various physical and psychological changes and improve CHD patients' quality of life, Cardiac Rehabilitation (CR) program is a practical option (Intarakamhang \& Intarakamhang, 2013; Yohannes et al., 2010). Janssen et al. (2013) construed that CR might change patients' disease-related perception to improve their quality of life. Furthermore, a CR program, which was carried out comprehensively, had been shown to reduce mortality and morbidity among patients with heart disease (Yohannes et al., 2010).

$\mathrm{CR}$ is divided into four phases. According to Radi et al. ( 2009), phase I CR is an effort immediately carried out while the patient is treated in the hospital. This phase's main objective is to reduce or eliminate the adverse effects of "decondition" due to prolonged bed rest. Early education is also carried out so that the patient can carry out daily activities independently and safely. Phase II is carried out immediately after the patient is discharged from the hospital to return to optimal function, control risk factors as early as possible, and provide additional education and counseling regarding a healthy lifestyle. These two CR phases are performed in the hospital on an outpatient basis. Phase III and IV are maintenance phases. It is expected that the patient will be able to independently complete a rehabilitation program safely at the same time as maintain a healthy lifestyle.

A phase II CR is a multidisciplinary program with comprehensive services (doctors, nurses, and nutritionists) including medical evaluation, recommended physical exercise, modification of risk factors through education and counseling, and strengthening the coping abilities of patients with the disease process (Dalal et al., 2015; Daly et al., 2002). However, the psychological aspects of the CR program received less attention, even though many research results have shown that these factors contributed to the pathogenesis and the development of heart disease (Kala et al., 2016). CR and exercise training which is carried out comprehensively, according to Lavie et al. (2016) improved psychological function and reduced the risk factors of mortality in people with heart disease. Several studies in Iran, the US, and the UK showed that psychological factors such as stress, anxiety and depression could be lowered through CR (Hoseini et al., 2013; Lavie et al., 2016; Mozafari et al., 2016; Yohannes et al., 2010). In contrast, several studies on phase II CR in Indonesia reclined more emphasis on the effects of CR on clinical outcomes, health behaviour, quality of life (Herliani et al., 2015; Rachma, 2018; Sutantri et al., 2019), and barriers to participating in CR (Stevani et al., 2018). Meanwhile, the effect of $\mathrm{CR}$ on the improvement of psychological conditions among CHD patients has not been found. Correspondingly, it is important to evaluate the effectiveness of a CR program in managing the physical and psychological problems.

One of the psychological problems that are essential to investigate is depression. According to Frost (2019), CHD patients had an increased risk of mental health problems after a heart attack with a higher prevalence of depression indicated in CHD people than the average population. These included major depressive disorder, which affected 
Aan Nuraeni: Depression, Recurrence, and Perceptions of Physical Fitness among CHD Patients

$20 \%$ of patients experienced a heart attack in the U.S. Moreover, major depressive symptoms can last a long time. Moreover, depression was the strongest predicting factor in decreasing the quality of life among CHD patients in Indonesia (Nuraeni et al., 2016; Nurhamsyah, 2019). Another research discovered that depression increased the risk of death in people with CHD and was added as a risk factor for cardiovascular disease by the American Heart Association (AHA) (Lichtman, Froelicher, Blumenthal, Carney, Lynn, et al., 2014).

The effect of CR in improving the condition of patients with heart problems has been widely proven. However, according to Yohannes et al. (2010), adaptation and evaluation of the program need to be carried out continuously attributable to differences in clinical populations, setting of implementation, and variations in health behaviour. Considering that there was only a few information on how the CR program affected the physical and psychological aspects of people with CHD in Indonesia, further exploration deserved to be conducted. Therefore, this study aimed to identify the comparison of depression, recurrence frequency, and perceptions of physical fitness among CHD patients who participated and did not participate in the CR program. It was expected that this research could provide the latest information on the extent of the CR program effectiveness on physical and psychological aspects of CHD patients, especially phase II.

\section{Method}

This study used secondary data from a previous Indonesian study by Stevani et al., (2018) about inhibiting factors of phase II CR among patients who actively participated and inactively participated in the program. This research utilized quantitative comparative analyses with a cross-sectional approach. This study included all patients with coronary heart disease who were eligible for phase II CR I at a referral hospital in Bandung, West Java, Indonesia. A purposive sampling technique was used with inclusion criteria: patients diagnosed with CHD (Unstable angina pectoris, NSTEMI, STEMI) with or without reperfusion therapy (fibrinolysis therapy, PCI, CABG). Patients were assigned to the CR group if they had at least six cardiac rehabilitation sessions. In contrast, patients were assigned to the non-CR group if being declared eligible for phase II CR by attending cardiologists but did not participate in the CR program. Patients attended CR program for less than six sessions were excluded in this study.

The sample size was calculated using the formula to compare two proportions, as follows:

$\mathrm{n}=(\mathrm{Z} \alpha / 2+\mathrm{Z} \beta) 2 *(\mathrm{p} 1(1-\mathrm{p} 1)+\mathrm{p} 2(1-\mathrm{p} 2)) /(\mathrm{p} 1-$ p2)2

$\mathrm{Z} \alpha / 2$ for confidence level of $90 \%$, with the critical value is $1.645 ; \mathrm{Z} \beta$ for a power of $80 \%$, the critical value is 0.84 ; and the difference in proportion (P1-P2) was considered significant at 30 (Wang \& Chow, 2007). Based on the calculation, the sample size was 31 for each group. However, the number of samples in the group participating in the CR was only 29 patients, fulfilling by $94 \%$ of the expected target. On the other hand, 37 patients were included in the nonCR group. Overall, 66 patients were recruited as samples in this study.

Depression measurements were carried out using the Beck Depression Inventory-II (BDI II) (Beck et al., 1996), which was translated into Indonesian and tested for validity and reliability in Indonesia's general population. Depression was categorized as follows: not depressed; mild depression; moderate depression; and major depression, based on a score range of $0-13 ; 14-19 ; 20-28$; and 29-63. The BDI II Indonesian version has a validity value of $r=0.39-0.52, p<0.01$, and Cronbach's $\alpha$ of 0.90 (Ginting et al., 2013).

To address the recurrence and perceptions of physical fitness, specific questions were developed. For recurrence, the question addressed towards the frequency of chest pain ("how often did you experience chest pain or tightness in the past month?" and each patient's response was recorded as: never (no symptoms of angina in the past month), rarely (ifless than one symptom of angina was felt in one week), often (if 2-6 times the symptoms of angina were felt in one week), very often (if 
more than six times the symptoms of angina were felt in one week. The measurement of chest pain frequency was based on the Seattle Angina Questionnaire (Spertus et al., 1995), taken from one of the questions that measure aspects of anginal frequency.

For perception of physical fitness, the question raised was "how did you perceive your physical fitness in the past month?" and each patient's response was recorded as: decreasing, unchanging, or increasing. The perceptions of physical fitness were based on the researcher's consideration. This perception was measured subjectively related to the respondent's perceived fitness in the last month without any validity construct.

Validity test was carried out for the question on frequency chest pain, which was compared with the recurrence perception of respondents using the Pearson product-moment, showing the value of r-count $(0.319)>$ r-table $(0.244)$ indicating that the question was valid. For reliability, a Cronbach's Alpha value was calculated at 0.526 .

Data were analyzed using frequency distributions for nominal and ordinal data, while for numerical data such as age and depression, mean scores were calculated. The comparative analyses were performed using chi-square tests for nominal and ordinal data with a significance value (p) $<.05$ and Mann-Whitney tests for numeric data with a significance value $(\mathrm{p})<.05$, and both test used 95\% CI. To minimize bias in interpreting the research results, two way
ANCOVA were performed at 95\% CI to adjust for initial differences between groups (McCarter, 2018). Covariates, including income, duration of being diagnosed with CHD, types of interventions, comorbid, and gender. The analysis was performed using IBM Statistics SPSS 20 software.

Before data collection, ethical approval was obtained from Universitas Padjadjaran Ethics Committee for Research No. 177 / UN6.C10 / PN / 2017. All respondents had been given sufficient information about the research and consents to participate. Moreover secondary data in this study were also used with permissions from related parties.

\section{Results}

Data were collected for three months, from February to April 2017, and obtained 66 respondents, consisting of 29 respondents who attended CR and 37 respondents who never attended CR. Most of the patients were male, aged over 55 years, and were married. A small proportion of respondents had been diagnosed with CHD for less than six months. However, almost all of the patient had undergone cardiac revascularization. Only $6 \%$ of the respondents did not revascularized. All patients who were not revascularized were in the non-CR group. The characteristics of the respondents in this study are more clearly shown in Table 1.

Table 1 Characteristics of Patients

\begin{tabular}{|c|c|c|c|c|c|c|}
\hline \multirow{3}{*}{ Characteristics } & \multicolumn{4}{|c|}{ Partcicipation in Cardiac Rehabilitation } & \multirow{3}{*}{$\begin{array}{c}\begin{array}{c}\text { Total } \\
(n=66)\end{array} \\
(n)\end{array}$} & \multirow{3}{*}{ p-value } \\
\hline & \multicolumn{2}{|c|}{ Non-CR(n=37) } & \multicolumn{2}{|c|}{ CR (n=29) } & & \\
\hline & (n) & $\begin{array}{c}\text { Percent } \\
(\%)\end{array}$ & (n) & $\begin{array}{c}\text { P e r c e n t } \\
(\%)\end{array}$ & & \\
\hline \multicolumn{7}{|l|}{ Gender } \\
\hline Male & 28 & 76 & 23 & 79 & 51 & $0.481^{\mathrm{b}}$ \\
\hline Female & 9 & 24 & 6 & 21 & 15 & \\
\hline Age*(mean) & \multicolumn{2}{|c|}{$58.54 \pm 8.5$} & \multicolumn{2}{|c|}{$56.86 \pm 8.7$} & & $0.547^{\mathrm{aa}}$ \\
\hline \multicolumn{7}{|l|}{ Education } \\
\hline No formal education & 1 & 3 & 0 & 0 & 1 & $0.689^{\mathrm{b}}$ \\
\hline
\end{tabular}


Aan Nuraeni: Depression, Recurrence, and Perceptions of Physical Fitness among CHD Patients

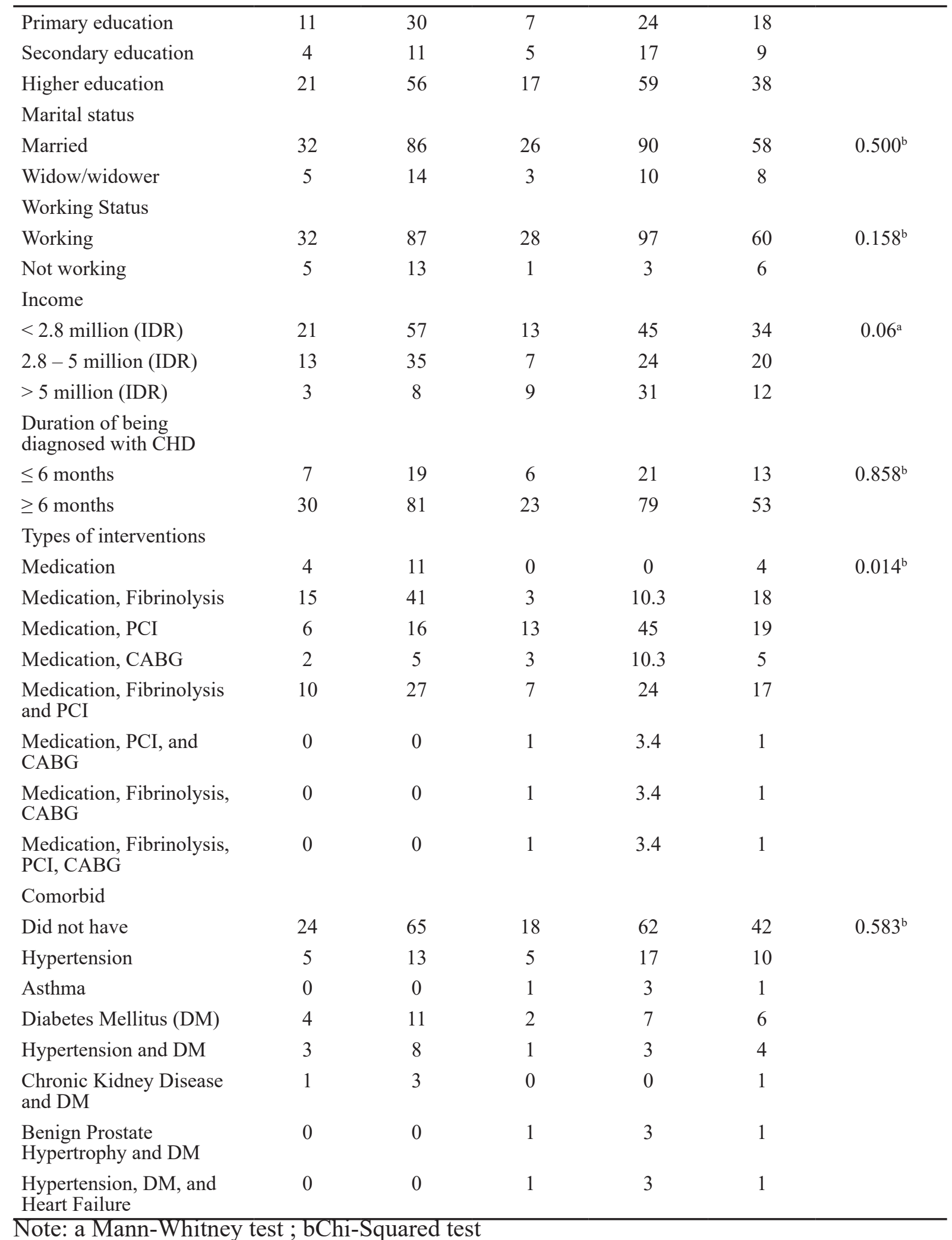

Note: a Mann-Whitney test ; bChi-Squared test 
Aan Nuraeni: Depression, Recurrence, and Perceptions of Physical Fitness among CHD Patients

Table 2 Differences in Depression, Frequency of Angina, and Perceptions of Fitness in Patients Based on Participation in CR Program

\begin{tabular}{|c|c|c|c|c|c|c|}
\hline \multirow{3}{*}{ Characteristics } & \multicolumn{4}{|c|}{ Participation in Cardiac Rehabilitation } & \multirow{3}{*}{ Total } & \multirow{3}{*}{$\underset{\text { value }}{\mathbf{p}}$} \\
\hline & \multicolumn{2}{|c|}{ Non-CR $(n=37)$} & \multicolumn{2}{|c|}{ CR $(n=29)$} & & \\
\hline & (n) & $\begin{array}{c}\text { Percent } \\
(\%)\end{array}$ & (n) & $\begin{array}{c}\text { Percent } \\
(\%)\end{array}$ & & \\
\hline Depression* (mean) & \multicolumn{2}{|c|}{$11.11 \pm 7.8$} & \multicolumn{2}{|c|}{$8.59 \pm 6.5$} & & $.114^{\mathrm{a}}$ \\
\hline \multicolumn{7}{|l|}{ Depression Category } \\
\hline Not depressed & 27 & 73 & 22 & 76 & 49 & .262 \\
\hline Mild depression & 6 & 16 & 4 & 14 & 10 & \\
\hline Moderate depression & 1 & 3 & 3 & 10 & 4 & \\
\hline Major depression & 3 & 8 & 0 & 0 & 3 & \\
\hline \multicolumn{7}{|c|}{$\begin{array}{l}\text { Chest pain frequency (last } \\
\text { one month) }\end{array}$} \\
\hline Never & 8 & 22 & 13 & 45 & 21 & .038 \\
\hline Rarely & 6 & 16 & 6 & 21 & 12 & \\
\hline Often & 15 & 40 & 3 & 10 & 18 & \\
\hline Very often & 8 & 22 & 7 & 24 & 15 & \\
\hline \multicolumn{7}{|l|}{ Perceived fitness level } \\
\hline Decreased & 20 & 54 & 0 & 0 & 20 & .000 \\
\hline Do not change & 17 & 46 & 3 & 10 & 20 & \\
\hline Increased & 0 & 0 & 26 & 90 & 26 & \\
\hline
\end{tabular}

Note: a Mann-Whitney test ; bChi-Squared test

Table 3 Effect of Income, Duration of Diagnosis of CHD, Type of Intervention, Comorbid, and Gender on The Dependent Variable (Depression, Frequency of Angina, and Perceptions of Fitness) in Patients Based on Participation in CR Program

\begin{tabular}{|c|c|c|c|}
\hline \multirow{3}{*}{ Characteristics } & \multicolumn{3}{|c|}{ Dependent variables } \\
\hline & Depression Category & $\begin{array}{c}\text { Perceived fitness } \\
\text { level }\end{array}$ & $\begin{array}{l}\text { Chest pain } \\
\text { frequency }\end{array}$ \\
\hline & p-value & p-value & p-value \\
\hline \multicolumn{4}{|l|}{ Gender } \\
\hline Male & .452 & .729 & .244 \\
\hline \multicolumn{4}{|l|}{ Female } \\
\hline \multicolumn{4}{|l|}{ Incomes } \\
\hline$<2.8$ million (IDR) & .417 & .256 & .231 \\
\hline \multicolumn{4}{|l|}{$2.8-5$ million (IDR) } \\
\hline \multicolumn{4}{|l|}{$>5$ million (IDR) } \\
\hline \multicolumn{4}{|l|}{ Had been diagnosed with CHD } \\
\hline$\leq 6$ months & .257 & .612 & .129 \\
\hline \multicolumn{4}{|l|}{$\geq 6$ months } \\
\hline Types of interventions & & & \\
\hline
\end{tabular}


Aan Nuraeni: Depression, Recurrence, and Perceptions of Physical Fitness among CHD Patients

Medication
Medication, Fibrinolysis
Medication, PCI
Medication, CABG
Medication, Fibrinolysis and PCI
Medication, PCI, and CABG
Medication, Fibrinolysis, CABG
Medication, Fibrinolysis, PCI, CABG
Comorbid
Did not have
Hypertension
Asthma
Diabetes Mellitus (DM)
Hypertension and DM
Chronic Kidney Disease and DM
Benign Prostate Hypertrophy and DM
Hypertension, DM, and Heart Failure
Note: Using the two Ways ANCOVA test, with a significance level of p <.05

Table 2 shows a significant difference in chest pain frequency and perceived fitness between patients who participated and did not participate in CR. However, there was no significant difference in depression in both groups.

Table 3 Effect of income, duration of diagnosis of CHD, type of intervention, comorbid, and gender on the dependent variable (depression, frequency of angina, and perceptions of fitness) in patients based on participation in CR Program.

Table 3 shows no effect on the covariate variables consisting of income, duration of diagnosis of CHD, types of interventions, comorbid, and gender on the dependent variable in this study i(depression, frequency of angina, and perceptions fitness), represented by a p-value $>.05$. This value signifies that the covariate variable does not influence the comparison between the two groups' dependent variable.

\section{Discussion}

Based on the analysis results, the existing CR program contributed to a marked difference in the improvement of physical function, but not the patients' psychosocial problem.
The improvement of physical function can be weighed by the frequency of chest pain and the perception of physical fitness. CHD patients participating in $\mathrm{CR}$ had a more higher proportion of those experienced no chest pain within the past month. In contrast, the majority of CHD patients who did not participated in $\mathrm{CR}$ experienced a much worse chest pain. The findings of this study support previous study (Yohannes et al., 2010), which found that CR provides better physical function results and reduces the risk of depression in people with CHD.

The results also suggested that non-CR groups had a higher percentage of chest pain frequency with a higher intensity. This condition may occur because, in CR, the physical activity ability of a CHD patient is enhanced through regular physical exercise and measured to increase the functional capacity of the body closer to the pre-heartattack condition. Studies on CHD patients undergoing CR have shown a better physical condition, marked by increased energy level, physical function, general health, and chest pain improvement (Dalal et al., 2015; Schopfer \& Forman, 2016; Yohannes et al., 2010). In this way, the existing CR program so far, effectively improved the physical aspects, immensely improved chest pain 
Aan Nuraeni: Depression, Recurrence, and Perceptions of Physical Fitness among CHD Patients

frequency and increased fitness perception in patients participating $\mathrm{CR}$ at least six times regularly.

The decrease in the frequency and intensity of chest pain in patients undergoing CR may be associated with increased maximal oxygen uptake (VO2max) ability. As previously known, an increase in oxygen demand without an adequate oxygen supply to the heart cause chest pain due to anaerobic metabolism that produces lactic acid. Several studies have shown that physical exercise carried out over a long time, and immediately after heart problems has been shown to improve VO2 max ability in CHD (Valkeinen et al., 2010). This improvement in oxygen uptake ability prevents anaerobic metabolism, which reduces the frequency and intensity of chest pain.

Exercise was also able to improve the physical functional capacity of CHD patients undergoing CR (Dalal et al., 2015; Menezes et al., 2014; Yohannes et al., 2010), which in this study was reported indirectly through perceptions of physical fitness. Perceived fitness was observed to be better in CHD patients participating in the CR program than in the non-participating group of patients. Perceived fitness was also closely related to the frequency and levels of chest pain that were noted to be higher in the non-CR group. Therefore, results indicate the effectiveness of CR program in improving the physical aspects of CHD patients. The findings also corroborate previous studies which found that $\mathrm{CR}$ is positively correlated with physical improvement and physical capacity of CHD patients (Herliani et al., 2015; Lavie et al., 2016; Lippi et al., 2016; Rutledge et al., 2013; Schopfer \& Forman, 2016; Yohannes et al., 2010).

In terms psychosocial aspects measured by the level of depression in this study, there was no difference in depression among CHD patients in both non-CR and CR groups. This indicates that the effectiveness of current CR program on the psychological aspects presents a room for improvement. The comprehensive implementation of CR impacts on improving physical and psychological problems as well as improving the quality of life. The results of a meta-analysis conducted by Gellis and KangYi (2012) show that in general, CR programs combined with psychosocial interventions are effective in reducing depression in adult cardiac patients compared to the standard treatments. Two studies conducted in Iran also showed that $\mathrm{CR}$ effectively reduced depression in both CHD patients undergoing PCI and CABG (Hoseini et al., 2013; Mozafari et al., 2016). Mozafari et al., (2016) further explained that post-CABG patients in the intervention group underwent eight $\mathrm{CR}$ meetings, which were held for four weeks, and each week was given two sessions. The training program provided includes a fitness program and education. Education materials provided were the use of drugs and diet and weight control, smoking cessation, stress management, relaxation, and light physical exercise.

The lack of significant differences in depression between non-CR and $\mathrm{CR}$ groups in this study could be attributable to several reasons. Referring to previous research, CR can positively impact depression if done comprehensively, including physical and psycho-spiritual aspects. Conversely, if CR is done partially, in this case, it focuses more on the patient's physical aspects and overlooks the psychological aspects, then this will lead to undetectable psychological problems. Another reason is that the measurement of depression might be too fast so that the patient has not achieved the expected psychosocial changes. As revealed in a previous study, a decrease in depression in post-CABG CHD patients was evident after undergoing eight CR meetings (Mozafari et al., 2016). In contrast to Mozafari et al. (2016), in this study, the majority of the patients in the CR group had only participated at least six meetings. Furthermore, in both groups, some patients had mild and moderate depression. If the score changed, the change would not significantly change the depression category result. The results of the previous meta-analysis confirm this reason. In previous studies, it was explained that CR's ineffectiveness in reducing depression in some studies could occur as a result of measuring depression too quickly. Some patients were in the mild and moderate depression category, and some patients had undergone CR for a long time before the study was conducted (Gellis \& Kang-Yi, 2012). 
However, even though there was no significant difference in depression between these two groups, the incidence of depression in the CR group was lower. The results can be specified from the lower mean depression score in the CR group, and all patients with severe depression were in the non-CR group. This study provides information for health workers in the care of patients with CHD and CR. In general, the average depression score for all patients is low; however, it was found that approximately $25.7 \%$ of patients experienced mild to severe depression.

Depression in CHD patients is a psychosocial problem that is often experienced and has a negative impact. Lichtman, Froelicher, Blumenthal, Carney, Doering, et al. (2014) stated that the risk of death is higher in CHD patients who experience depression. This result was also upheld by $\mathrm{Gu}$ et al. (2019) that depression was an independent prognostic factor for all causes of death and other cardiovascular problems in patients with Myocardial Infarction with non obstructive coronary arteries (MINOCA) in China. Whereas in Indonesia, two studies showed that depression was the most influential factor in reducing CHD patients' quality of life (Nuraeni et al., 2016; Nurhamsyah, 2019). This condition implies the importance of prevention and management of depression. Depression warrants considerable attention from healthcare professionals treating CHD patients. Existing $\mathrm{CR}$ program needs to be revisited to ensure it provides adequate psychosocial interventions in conjunction with the physical exercise. Moreover, overall effectiveness of CR program in CHD patients requires a continuous evaluation.

\section{Conclusion}

Patients who participated in CR program had a better perception of physical fitness and experienced a lower frequency of angina than patients who did not participate in the program. Concerning depression, there was no significant difference in patients in both non-CR and CR groups.

In this study, the improvement in physical aspects did not significantly affect the improvement of depression within the two groups. It is recommended optimizing the implementation of counseling and other psychosocial problem interventions in the $\mathrm{CR}$ program. It is also necessary to carry out a further evaluation of the effectiveness of the CR program with a larger number of parameters and patients as well as a more objective measuring tool.

\section{References}

Beck, A. T., Steer, R. A., Ball, R., \& Ranieri, W. F. (1996). Comparison of Beck Depression Inventories-IA and-II in psychiatric outpatients. Journal of personality assessment, 67(3), 588-597. https://doi. org/10.1207/s15327752jpa6703_13

Dalal, H. M., Doherty, P., \& Taylor, R. S. (2015). Cardiac rehabilitation. BMJ, 5000(September), 1-8. https://doi. org/10.1136/bmj.h5000

Daly, J., Sindone, A. P., Thompson, D. R., Hancock, K., Chang, E., \& Davidson, P. (2002). Barriers to participation in and adherence to cardiac rehabilitation programs: a critical literature review. Progress in Cardiovascular Nursing, 17(1), 8-17. https:// doi.org/10.1111/j.0889-7204.2002.00614.x

Frost, J. (2019). Practice Guidelines Depression Following Acute Coronary Syndrome Events : Screening and Treatment Guidelines from the AAFP. American Family Physician, 99(15), 786B-786J.

Gellis, Z. D., \& Kang-Yi, C. (2012). Meta-analysis of the Effect of Cardiac Rehabilitation Interventions on Depression Outcomes in Adults 64 Years of Age and Older. American Journal of Cardiology, 110(9), 1219-1224. https://doi.org/10.1016/j. amjcard.2012.06.021

Ginting, H., Näring, G., Van Der Veld, W. M., Srisayekti, W., \& Becker, E. S. (2013). Validating the Beck Depression InventoryII in Indonesia's general population and coronary heart disease patients. International Journal of Clinical and Health Psychology, 
13(3), 235-242. https://doi.org/10.1016/ S1697-2600(13)70028-0

Gu, X., He, C., Shen, L., \& Han, B. (2019). Association Between Depression and Outcomes in Chinese Patients With Myocardial Infarction and Nonobstructive Coronary Arteries. Journal of the American Heart Association, 1-6. https://doi. org/10.1161/JAHA.118.011180

Herliani, Y. K., Matchim, Y., \& Kritpracha, C. (2015). Health Behaviors and Clinical Outcomes Among Patients with Myocardial Infarction in Indonesia. Jurnal NERS, 10(2), 308. https://doi.org/10.20473/ jn.v10i22015.308-317

Hoseini, S., Soltani, F., Babaee Beygi, M., \& Zarifsanaee, N. (2013). The effect of cardiac rehabilitation on anxiety and depression in patients undergoing cardiac bypass graft surgery in Iran. Journal of Clinical Nursing, 22(11-12), 1613-1619. https://doi. org/10.1111/jocn.12125

Indrawati, L. (2012). Analisis Faktor Yang Berhubungan Dengan Kemampuan Pasien PJK Melakukan Pencegahan Sekunder Faktor Risiko Di RSPAD Gatot Soebroto Jakarta. [Master's thesis, University of Inonesia]. Universitas Indonesia. Retrieved February 2, 2020, from https://lib.ui.ac. $\mathrm{id} /$ file? file=digital/20313795-T\%20 31743-Analisis\%20faktor-full\%20text.pdf

Intarakamhang, P., \& Intarakamhang, U. (2013). Effects of the comprehensive cardiac rehabilitation program on psychological factors and quality of life among coronary heart disease patients. Global Journal of Health Science, 5(2), 145-152. https://doi. org/10.5539/gjhs.v5n2p145

Janssen, V., De Gucht, V., Van Exel, H., \& Maes, S. (2013). Changesinillness perceptions and quality of life during participation in cardiac rehabilitation. International Journal of Behavioral Medicine, 20(4), 582-589. https://doi.org/10.1007/s12529-012-9260-3

Kala, P., Hudakova, N., Jurajda, M., Kasparek, T., Ustohal, L., Parenica, J., Sebo, M.,
Holicka, M., Kanovsky, J., Thombs, B., Bass, E., Ford, D., Stewart, K., Tsilidis, K., Patel, U., Lane, D., Carroll, D., Ring, C., Beevers, D., ... Zung, W. (2016). Depression and Anxiety after Acute Myocardial Infarction Treated by Primary PCI. Plos One, 11(4), e0152367. https://doi.org/10.1371/journal. pone. 0152367

Lavie, C. J., Menezes, A. R., De Schutter, A., Milani, R. V., \& Blumenthal, J. A. (2016). Impact of Cardiac Rehabilitation and Exercise Training on Psychological Risk Factors and Subsequent Prognosis in Patients with Cardiovascular Disease. Canadian Journal of Cardiology. https://doi.org/10.1016/j. cjca.2016.07.508

Lichtman, J. H., Froelicher, E. S., Blumenthal, J. A., Carney, R. M., Lynn, V., Frasure-smith, N., Freedland, K. E., Jaffe, A. S., Leifheitlimson, E. C., Sheps, D. S., Vaccarino, V., \& Wulsin, L. (2014). Depression as a Risk Factor for Poor Prognosis Among Patients With Acute Coronary Syndrome: Systematic Review and Recommendations. https://doi. org/10.1161/CIR.0000000000000019

Lippi, G., Sanchis-Gomar, F., \& Cervellin, G. (2016). Chest pain, dyspnea and other symptoms in patients with type 1 and 2 myocardial infarction. A literature review. International Journal of Cardiology, $215, \quad 20-22 . \quad$ https://doi.org/10.1016/j. ijcard.2016.04.045

McCarter, K. S. (2018). Analysis of Covariance (pp. 235-277). https://doi. org/10.2134/appliedstatistics.2016.0006.c9

Menezes, A. R., Lavie, C. J., Milani, R. V, Forman, D. E., King, M., \& Williams, M. A. (2014). Cardiac Rehabilitation in the United States. Progress in Cardiovascular Diseases, 56(5), 522-529. https://doi.org/10.1016/j. pcad.2013.09.018

Ministry of Health of the Republic of Indonesia. (2018). Hasil Riset Kesehatan Dasar 2018 (Basic Health Research Results). Retrieved January 28, 2020, from http:// labdata.litbang.depkes.go.id/menu-progresspuldata/progress-puldata-rkd-2018 
Aan Nuraeni: Depression, Recurrence, and Perceptions of Physical Fitness among CHD Patients

Mozafari, A., Baharvand, A., Mohebi, S., \& Hejazi, S. F. (2016). Impact of Cardiac Rehabilitation on Depression after Percutaneous Coronary Intervention. Journal of Health, 7(3), 356-364.

Nuraeni, A., Mirwanti, R., Anna, A., \& Nurhidayah, I. (2019). Determinant Factors of Depression in Patients with Coronary Heart Disease. Padjadjaran Nursing Journal, 7(3), 246-254. https://doi.org/10.24198/jkp

Nuraeni, A., Mirwanti, R., Anna, A., Prawesti, A., \& emaliyawati, etika. (2016). Faktor yang Memengaruhi Kualitas Hidup Pasien dengan Penyakit Jantung Koroner. (Factors Affecting Quality of Life of Patients with Coronary Heart Disease). Jurnal Keperawatan Padjadjaran, 4(2). https://doi. org/10.24198/jkp.v4i2.231

Nurhamsyah, D. (2019). Analisis Faktor yang Berhubungan Dengan Kualitas Hidup Pasien Pasca Sindrom Koroner Akut Di RSUP DR. Hasan Sadikin Bandung. (Analysis of Factors Associated with Quality of Life of PostAcute Coronary Syndrome Patients at RSUP DR. Hasan Sadikin Bandung). Universitas Padjadjaran.

Rachma, N. (2018). Effect of Cardiac Rehabilitation on NT-Pro BNP, METS, and Quality of Life, in Patients with Coronary Artery Disease after Undergoing Percutaneous Coronary Intervention. Indonesian Journal of Medicine, 3(3), 146-150. https://doi. org/10.26911/theijmed.2018.03.03.04.

Rachmi, F., Nur'aeni, A., \& Mirwanti, R. (2018). Kecemasan Berhubungan Dengan Frekuensi Agina: Studi Korelatif Pada Pasien Pasca Sindrom Koroner Akut. (Anxiety Associated with Angina Frequency: Correlative Study in Post-Acute Coronary Syndrome Patients). Medisains: Jurnal Ilmiah Ilmu-Ilmu Kesehatan, 16(1-7).

Radi, B., Joesoef, A. H., \& Kusmana, D. (2009). Rehabilitasi Kardiovaskular Di Indonesia. (Cardiovascular Rehabilitation In Indonesia). Majalah Kardiologi Indoneisa., 30(2), 43-45. Retrieved 28 January, 2020, from indonesia.digitaljournals.org/index. php/karidn/article/.../311/310?

Rosidawati, I., Ibrahim, K., Nuraeni, A., Muhammadiyah, U., Keperawatan, F., \& Padjadjaran, U. (2016). Kualitas Hidup Pasien Pasca Bedah Pintas Arteri Koroner ( BPAK ). (Quality of Life among Patients with Post Coronary Artery Bypass Surgery). Jurnal Keperawatan Padjadjaran, 4, 151161. https://doi.org/10.24198/jkp.v4i2.238

Rutledge, T., Redwine, L. S., Linke, S. E., \& Mills, P. J. (2013). A meta-analysis of mental health treatments and cardiac rehabilitation for improving clinical outcomes and depression among patients with coronary heart disease. Psychosomatic Medicine, 75(4), 335-349. https://doi.org/10.1097/ PSY.0b013e318291d798

Schopfer, D. W., \& Forman, D. E. (2016). Benefits of cardiac rehabilitation in older adults. American College of Cardiology. Retrieved January 28, 2020, from https:// www.acc.org/latest-in-cardiology/ articles/2016/10/19/09/22/benefits-ofcardiac-rehabilitation-in-older-adults

Spertus, J. A., Winder, J. A., Dewhurst, T. A., Deyo, R. A., Prodzlnski, J., Mcdonell, M., \& Fihn, S. D. (1995). Development and Evaluation I ? f the Seattle Angina Questionnaire: A New Functional Status Measure for Coronary Artery Disease. 25(2). https://doi.org/10.1016/07351097(94)00397-9

Stevani, M. D., Nuraeni, A., \& Sari, E. A. (2018). The Distinction of Inhibiting Factors among Patients who Actively and Inactively Participate in Phase II Cardiac Rehabilitation. Jurnal Keperawatan Padjadjaran, 6(2), 109119. https://doi.org/10.24198/jkp.v6i2.550

Sutantri, S., Cuthill, F., \& Holloway, A. (2019). 'A bridge to normal': a qualitative study of Indonesian women's attendance in a phase two cardiac rehabilitation programme. European Journal of Cardiovascular Nursing, 18(8), 744-752. https://doi. org/10.1177/1474515119864208

Valkeinen, H., Aaltonen, S., \& Kujala, U. 
Aan Nuraeni: Depression, Recurrence, and Perceptions of Physical Fitness among CHD Patients

M. (2010). Effects of Exercise Training on Oxygen Uptake in Coronary Heart Disease: A systematic Review and Meta-analysis. Scandinavian Journal of Medicine and Science in Sports, 20(4), 545-555. https:// doi.org/10.1111/j.1600-0838.2010.01133.x

Wang, \& Chow. (2007). Sample Size Calculation for Comparing Proportions.
Wiley Encyclopedia of Clinical Trials.

Yohannes, A. M., Doherty, P., Bundy, C., \& Yalfani, A. (2010). The long-term benefits of cardiac rehabilitation on depression, anxiety , physical activity and quality of life. Journal of Clinical Nursing, 19, 2806-2813. https:// doi.org/10.1111/j.1365-2702.2010.03313.x 